\title{
Chlorophyll $a$ interference in phycocyanin and allophycocyanin spectrophotometric quantification
}

\author{
Rosaria LAUCERI, ${ }^{*}$ Mariano BRESCIANI, ${ }^{2}$ Andrea LAMI, ${ }^{1}$ Giuseppe MORABITO ${ }^{1}$ \\ ${ }^{1}$ National Research Council of Italy, Institute for the Study of Ecosystems, Largo Tonolli 50, 28922 Verbania-Pallanza; \\ ${ }^{2}$ National Research Council of Italy, Institute for Electromagnetic Sensing of the Environment, Optical Sensing Group, via Bassini \\ 15, 20133 Milan, Italy \\ *Corresponding author: r.lauceri@ise.cnr.it
}

\begin{abstract}
The accurate quantification of cyanobacteria phycobiliproteins is an important aspect in various research topics, such as cyanobacteria ecology and physiology studies, and especially to calibrate algorithms used in remote sensing of cyanobacterial blooms. Here we present a spectroscopic approach, exploiting spectrophotometric equations, aimed at improving the phycocyanin and allophycocyanin quantification when chlorophyll $a$ is present in the phycobiliprotein aqueous extract.
\end{abstract}

Key words: Cyanobacteria; phycocyanin; allophycocyanin; chlorophyll $a$; spectrophotometric equation.

Received: July 2017. Accepted: September 2017.

\section{INTRODUCTION}

Photosynthetic organisms use various chlorophyll molecules and several accessory pigments to improve their efficiency in capturing solar radiation. Generally, cyanobacteria contain chlorophyll $a(\mathrm{Chl} a)$ only together with different carotenoids as accessory pigments: moreover, to maximize the photosynthetic efficiency, they have the phycobiliproteins (chromophore-protein covalently linked compounds). Because only a few other algal classes (rhodophytes and cryptophytes) possess these pigments, they can be used as a valuable proxy to detect the presence of cyanobacteria in mixed phytoplankton assemblages (Seppälä et al., 2007; Escoffier et al., 2015).

The most common phycobiliproteins are phycocyanins (PCs), allophycocyanins (APCs) and phycoerythrins (PEs); they harvest light and deliver it toward photosystem I and photosystem II through energy transfer processes flowing from PEs (high energy) to PCs (intermediate energy) to APCs (low energy) and, finally, to photosystem I and II, containing Chla (lowest energy level) (Gantt, 1975; Zhao et al., 2015). In vivo, these pigments are organized in protein complexes, the phycobilisomes, which are (as the phycobiliproteins themselves) water soluble. Chlorophylls (Chls) are typically extracted in various organic solvents, e.g. methanol or acetone, and they are rather stable if kept in appropriate conditions. Conversely, phycobilisomes/phycobiliproteins are denatured and almost depigmented after exposure to organic solvents (Cohen-Bazire and Bryant, 1982; MacColl, 1983), and, therefore, they are commonly extracted in phosphate buffer solution at neutral (or slightly acidic) pH. In aqueous solvents, phycobiliproteins may dissociate, forming lower weight complexes, depending on the organism of origin as well as on the extraction conditions, such as the solvent, the ionic-strength, the $\mathrm{pH}$ and their own concentration (MacColl, 1983; Glazer, 1988; Berns and MacColl, 1989). The main components of phycobiliproteins are protein subunits $\alpha$ and $\beta$, which form the monomeric unit $(\alpha \beta)$. When extracted and purified from cyanobacteria, PEs show an absorption maximum at 495 and 540-570 $\mathrm{nm}$ (a very stable complex containing the hexamer unit $\left.(\alpha \beta)_{6}\right)$, PCs have an absorption maximum around 615-620 $\mathrm{nm}$ (monomer-trimer), and APCs around $650 \mathrm{~nm}$ (trimer) (Glazer and Hixson, 1977; MacColl, 1998).

In addition to Chla determination (Richardson et al., 2010; MacIntyre et al., 2011), a better evaluation of cyanobacterial contribution to the total phytoplankton biomass can be achieved by an accurate quantification of phycobiliproteins, taking into account their specific absorbance peak. However, this is not a simple task to achieve with a spectrophotometric analysis, because the absorbance bands of these pigments (PCs and APCs, in particular) overlap with those of Chls and produce a bias in their quantitative determination even in the aqueous extracts (Myers and Kratz 1955; Sarada et al., 1999; Yacobi et al., 2015), where Chla may be present if a not mild extraction protocol is used (the efficacy of an extraction protocol is species-specific; not always mild extraction protocols are applicable, due to the great resistance a cyanobacterium cell wall can have). Chla bias might be critical in some research applications such as in vivo fluo- 
rescence calibration (Kasinak et al., 2015; Macário et al., 2015) and the development of a more appropriate coefficient for the semi-empirical algorithms and specific inherent optical properties for the bio-optical model to apply at the satellite images in remote sensing for cyanobacteria monitoring (Schalles and Yacobi, 2000; Simis et al., 2007; Bresciani et al., 2011; Ogashawara et al., 2013; Mishra and Mishra, 2014), as well as insight into the physiology and ecology of cyanobacterial species (e.g., complementary chromatic adaptation; Bennett and Bogorad, 1973; De Marsac and Houmard, 1988; Li et al., 2016).

An obvious requisite of any quantification method is to obtain an extraction as complete as possible of the target pigments. Various extraction methods have been proposed in literature (Quesada and Vincent, 1993; Sarada et al., 1999; Lawrenz et al., 2011; Zimba, 2012; Horváth et al., 2013), but their efficiency is variable and the protocols often need to be optimized for the particular cyanobacterial species investigated (Lawrenz et al., 2011; Horváth et al., 2013).

In addition, a common drawback of these extraction protocols is that improving extraction efficiency can also be associated with an increasing concurrent extraction of Chls (Myers and Kratz, 1955; Sarada et al., 1999; Yacobi et al., 2015). The overlap of Chl absorption bands with those of PCs and APCs in the 600-700 nm range affects the correct determination of these accessory pigments when they are quantified by absorbance measurements. In fact, the spectroscopic quantification equations commonly used are those proposed by Bennett and Bogorad (1973), in which they assume that only different phycobiliproteins are present, but no Chls. In literature, Bennett and Bogorad equations are invariably applied regardless the possible presence of Chls in the solution (Sarada et al., 1999; Zhu et al., 2007; Zimba, 2012; Horváth et al., 2013; Yacobi et al., 2015).

The aims of this study were i) to show that PC and APC quantification, performed applying Bennett and Bogorad equations regardless the possible presence of Chls, can be affected by huge errors; and ii) to develop a methodological approach to minimize the error in phycobiliproteins quantification due to chlorophyll presence in solution.

As testing material, we selected a laboratory culture of Microcystis aeruginosa, a unicellular freshwater organism often found in freshwater. We chose to study this species because i) it is most frequently linked to hepatotoxic blooms both in Italian lakes (Bruno et al., 2005) and worldwide (Chorus and Bartram, 1999); ii) it is possible to use a mild extraction procedure, obtaining phycobiliproteins extracts free from Chla, to be used as a reference. In fact, cyanobacteria phycobiliprotein extracts may be contaminated by Chla, when using extraction methods less mild than freeze-thawing, such as homogenisation in blender (Sarada et al., 1999) or sonication (Zhu et al., 2007).

Microcystis aeruginosa produces PC, APC and Chla; therefore, only the interference of Chla was considered in this study. We evaluated the amount of error caused by $\mathrm{Chl} a$, developing equations to correct the apparent $\mathrm{PC}$ and APC absorbance values, before quantifying phycobiliproteins according to Bennett and Bogorad (1973).

\section{METHODS}

\section{Cyanobacterial cultures}

The species Microcystis aeruginosa, Kützing 1846, strain 1885 (non-toxic), from the culture collection of the Laboratory of Algal Biology, University of Rome Tor Vergata, was used in this study. M. aeruginosa was maintained at $21^{\circ} \mathrm{C}$ in $600 \mathrm{~mL}$ flasks containing BG11 medium (Rippka et al., 1979) and mixed by air bubbling. Cultures were illuminated in continuous light with $15 \mu \mathrm{mol}$ photons $\mathrm{m}^{-2} \mathrm{~s}^{-1}$ supplied by cool white lamps (Lumilux T2 FM $11 \mathrm{~W} / 740$, Osram, Italy). Incident light on the surface of the cultures was measured with a Quantitherm combined PAR and temperature sensor (Hansatech Instruments).

\section{Extract spectroscopic analyses}

Absorbance measurements were carried out on a UVmc2 spectrophotometer (SAFAS), spectrofluorometric measurements were carried out on a FluoroMax-4 (HORIBA Scientific, Irvine, CA, USA). Suprasil quartz, $1 \mathrm{~cm}$ light path, cuvettes were used throughout. Absorbance values were always scatter-corrected by subtracting the absorbance at $750 \mathrm{~nm}$.

\section{Pigment extraction solvents}

Chl $a$ extraction was performed using $90 \%$ aqueous acetone [acetone chromasolv for HPLC, Sigma-Aldrich (St. Louis, MO, USA) and $18 \mathrm{M} \Omega$ Milli-Q water]; phosphate buffer $10 \mathrm{mM}, \mathrm{NaCl} 150 \mathrm{mM}, \mathrm{pH}$ 7, for Chla or phycobiliprotein extraction, was prepared with $18 \mathrm{M} \Omega$ Milli-Q water, sodium phosphate monobasic dehydrate (analytical grade; Acros Organics, Pittsburg, PA, USA) sodium chloride (ACS reagent; VWR Chemicals, Radnor, PA, USA), sodium hydroxide (ACS reagent; Sigma-Aldrich).

\section{Phycobiliprotein extraction}

The phycobiliproteins (PC and APC) stock solutions were obtained from $M$. aeruginosa culture after extraction with a sodium phosphate buffer $10 \mathrm{mM}, \mathrm{NaCl} 150 \mathrm{mM}, \mathrm{pH}$ 7 solution as in Bennett and Bogorad (1973), but a different extraction protocol was applied. In particular, a culture aliquot was put in a glass beaker and sonicated for about $30-40$ s (power $45 \%$, pulse $50 \%$, sonotrode $\mathrm{S} 2$, Hielscher Ultrasonic Processor UP200S, $200 \mathrm{~W}, 24 \mathrm{kHz}$ ) to break cell vacuoles (cells are not disrupted at this sonication power. Cell integrity was determined by microscopic examination. 
Moreover, the supernatant obtained after centrifugation was colourless) and facilitate the sedimentation in a $30 \mathrm{~mL}$ Kimax high strength centrifuge borosilicate glass tube. The suspension was centrifuged for $15 \mathrm{~min}\left(11,000 \mathrm{rcf}, \mathrm{t}=10^{\circ} \mathrm{C}\right)$ and the supernatant removed. The cyanobacterial pellet was suspended and washed with pure $18 \mathrm{M} \Omega$ Milli-Q water, then centrifuged for $15 \mathrm{~min}\left(11,000 \mathrm{rcf}, \mathrm{t}=10^{\circ} \mathrm{C}\right)$ and the supernatant removed. The pellet was suspended again in 5 $\mathrm{mL}$ of buffer and subjected to three freeze-thawing cycles: the glass tube was maintained at $-20^{\circ} \mathrm{C}$ for $3 \mathrm{~h}$, then thawed in a water bath at $20^{\circ} \mathrm{C}$; the procedure was repeated a second time. The third freeze-thawing cycle was performed after the addition of further $10 \mathrm{~mL}$ buffer $(15 \mathrm{~mL}$ buffer in total); the suspension was maintained at $-20^{\circ} \mathrm{C}$ overnight, thawed the morning after and maintained at $4^{\circ} \mathrm{C}$ for $24 \mathrm{~h}$. The solution was then centrifuged for $45 \mathrm{~min}$ (11,000 rcf, $\mathrm{t}=10^{\circ} \mathrm{C}$ ). The supernatant containing PC and APC (stock solution) was collected, stored at $4^{\circ} \mathrm{C}$ and used within 48 h. No Chl $a$ was present in solution, as evidenced by absorbance measurement. The concentration of phycobiliproteins was determined using Bennett and Bogorad equations (Bennett and Bogorad, 1973) slightly modified (absorbance (A) value at $620 \mathrm{~nm}$ (PC maximum in this study) was used instead of A at $615 \mathrm{~nm}$ ). The Chl $a$-free phycobiliprotein extract solutions were used as reference for Chla contaminated phycobiliprotein solutions. Using the same phycobiliprotein concentration in the Chla contaminated solution and in the correspondent Chla-free reference solution, it is possible to calculate the error in PC and APC quantification due to the presence of Chla and, consequently, it is possible to verify the efficacy of the corrective equations developed below.

The pellet obtained after PC and APC extraction was used as source of Chla (as described below) to contaminate phycobiliprotein solutions, simulating extraction processes which cause Chla contamination.

\section{Chlorophyll $a$ extraction}

Different extraction procedures were adopted in order to determine the best extraction protocol to correct the apparent PC and APC absorbance from Chla contribution.

In particular, Chla was obtained from M. aeruginosa using the following procedures: 1) extracted from the "untreated" cell pellets using aqueous acetone ( $90 \%$ acetone); 2) extracted from phycobiliprotein-free cell pellets using phosphate buffer (a) and phycobiliprotein extract in phosphate buffer (b).

\section{Procedure 1: Extraction solvent $90 \%$ acetone}

A culture aliquot was put in a glass beaker and sonicated for about $30-40 \mathrm{~s}$ (power $45 \%$, pulse $50 \%$, sonotrode S2, Hielscher Ultrasonic Processor UP200S, $200 \mathrm{~W}, 24 \mathrm{kHz}$ ) to break cell vacuoles (but not cell wall.
Cell integrity was determined by microscopic examination. Moreover, the supernatant obtained after centrifugation was colourless) and facilitate sedimentation in a 30 $\mathrm{mL}$ Kimax high strength centrifuge borosilicate glass tube. The suspension was centrifuged for $15 \mathrm{~min}(11,000$ $\left.\mathrm{rcf}, \mathrm{t}=10^{\circ} \mathrm{C}\right)$ and the supernatant removed. The cyanobacterial pellet was suspended and washed with pure $18 \mathrm{M} \Omega$ Milli-Q water, then centrifuged for $15 \mathrm{~min}(11,000 \mathrm{rcf}$, $\mathrm{t}=10^{\circ} \mathrm{C}$ ) and the supernatant removed. The pellet was mixed with $10 \mathrm{~mL} 90 \%$ acetone, sonicated four times for $60 \mathrm{~s}$ (power $75 \%$, pulse $60 \%$, sonotrode S2) in water/ice bath, with $60 \mathrm{~s}$ pause in-betweens (to avoid Chla degradation), and centrifuged for $45 \mathrm{~min}\left(11,000 \mathrm{rcf}, \mathrm{t}=10^{\circ} \mathrm{C}\right)$. The supernatant containing Chla (stock solution) was collected, the pellet discarded, disregarding total Chla extraction (it is not of interest here). Chla concentration was determined by absorbance (absorbance coefficient at 664 $\mathrm{nm}=11.406 \mu \mathrm{g} \mathrm{mL}^{-1} \mathrm{~cm} \mathrm{~A}^{-1}$; Ritchie, 2006). Chla stock solutions were stored at $4^{\circ} \mathrm{C}$ and used within $24 \mathrm{~h}$.

\section{Procedures 2a and 2b: Extraction solvent phosphate buffer}

In procedures $2 \mathrm{a}$ and $2 \mathrm{~b}$ Chla was extracted from the cyanobacteria pellets already used to extract the phycobiliproteins. After we obtained the phycobiliprotein stock solution, as described in the section "Phycobiliprotein extraction", the absence of PC and APC in the cell debris pellet was ascertained, before $\mathrm{Chl} a$ extraction, as follows: the pellet was suspended in $5 \mathrm{~mL}$ of buffer and freezethawed one time; after the addition of $10 \mathrm{~mL}$ buffer it was maintained at $4^{\circ} \mathrm{C}$ for $24 \mathrm{~h}$. The suspension was then centrifuged for $45 \mathrm{~min}\left(11,000 \mathrm{rcf}, \mathrm{t}=10^{\circ} \mathrm{C}\right)$ and the supernatant recovered and checked for the presence of $\mathrm{PC}$ and APC. After having verified the total extraction of $\mathrm{PC}$ and APC by absorbance, the supernatant was discharged and the pellet was used as source of Chla. The absence of phycobiliproteins in the pellet was also checked by fluorometric measurements on the pellet suspensions.

A concentrated pellet suspension was prepared in a few millilitres of phosphate buffer, which was used as stock solution. The appropriate volume of concentrated pellet suspension was $2 \mathrm{a}$ simply diluted in phosphate buffer or $2 \mathrm{~b}$ added to a solution of the two phycobiliproteins (PC and APC); after that, the resulting suspension solution was extracted. It was sonicated four times for $60 \mathrm{~s}$ (power $75 \%$, pulse $60 \%$, sonotrode S2) in water/ice bath, with 60 s pause in-betweens (to avoid Chla, PC and APC degradation), centrifuged for $45 \mathrm{~min}\left(11,000 \mathrm{rcf}, \mathrm{t}=10^{\circ} \mathrm{C}\right)$, and the supernatant collected for spectroscopic determinations.

\section{Spectrophotometric equations}

To correct PC and APC absorbance from Chla contribution, it was assumed that $\mathrm{Chl} a, \mathrm{PC}$ and $\mathrm{APC}$ ab- 
sorbances in buffer solution were additive. Considering the absorbance at $620 \mathrm{~nm}$ (PC maximum) and at $675 \mathrm{~nm}$ (Chla maximum in buffer) it follows:

$\mathrm{A}^{620}{ }_{\text {measured }}=\mathrm{A}^{620}{ }_{\mathrm{Phs}}+\mathrm{A}^{620}{ }_{\mathrm{Chl} a}$

$\mathrm{A}_{\text {measured }}^{675} \mathrm{~A}^{675}$ Phs $+\mathrm{A}^{675}$ Chla

$\mathrm{A}_{\text {Phs }}$ indicate the cumulative absorbance due to both phycobiliproteins.

$\mathrm{A}^{620} \mathrm{Chl} a$ can be expressed as fraction of Chla absorption at $675 \mathrm{~nm}$, using the ratio $\mathrm{A}^{620}{ }_{\mathrm{Chla}} / \mathrm{A}^{675} \mathrm{Chla}$

$\mathrm{A}^{675}$ Phs can be expressed as fraction of phycobiliprotein absorption at $620 \mathrm{~nm}$, using the ratio $\mathrm{A}^{620}{ }_{\text {Phs }} / \mathrm{A}^{675}{ }_{\text {Phs }}$.

The two equations can be written:

$\mathrm{A}^{620}{ }_{\text {measured }}=\mathrm{A}^{620}{ }_{\mathrm{Phs}}+\left(\mathrm{A}_{\mathrm{Chl} a}^{620} / \mathrm{A}_{\mathrm{Chl} a}^{675}\right) \times \mathrm{A}_{\mathrm{Chl} a}^{675}$

$\mathrm{A}_{\text {measured }}^{675}\left(\mathrm{~A}_{\text {Phs }}^{620} /\left(\mathrm{A}_{\mathrm{Phs}}^{620} / \mathrm{A}^{675}{ }_{\mathrm{Phs}}\right)\right)+\mathrm{A}_{\mathrm{Chl} a}^{675}$

Resolving this two-equation system, the equation to correct the absorbance of phycobiliproteins at $620 \mathrm{~nm}$ can be easily obtained:

$\mathrm{A}^{620}{ }_{\mathrm{Phs}=} \mathrm{a}^{-1} \mathrm{~A}^{620}{ }_{\text {measured }}-\mathrm{b} \mathrm{A}^{675}{ }_{\text {measured }}$

with

$\mathrm{a}=1-\left[\left(\mathrm{A}_{\mathrm{Chl} a}^{620} / \mathrm{A}_{\mathrm{Chl} a}^{675}\right) /\left(\mathrm{A}_{\mathrm{Phs}}^{620} / \mathrm{A}_{\mathrm{Phs}}^{675}\right)\right]$

$\mathrm{b}=\left[\left(\mathrm{A}_{\mathrm{Chl} a}^{620} / \mathrm{A}_{\mathrm{Chl} a}^{675}\right) / \mathrm{a}\right]$

Similarly, considering the absorbance at $652 \mathrm{~nm}$ (APC maximum) and at $675 \mathrm{~nm}$, applying the same procedure and using the ratios $\mathrm{A}_{\text {Chla }}^{652} / \mathrm{A}^{675}{ }_{\mathrm{Chl} a}$ and $\mathrm{A}^{652}{ }_{\mathrm{Phs}} / \mathrm{A}^{675}{ }_{\mathrm{Phs}}$, the equation to correct the absorbance of phycobiliproteins at $652 \mathrm{~nm}$ is obtained:

$\mathrm{A}^{652}{ }_{\text {Phs }}=\mathrm{c}^{-1} \mathrm{~A}^{652}{ }_{\text {measured }}-\mathrm{d} \mathrm{A}^{675}{ }_{\text {measured }}$

with

$\mathrm{c}=1-\left[\left(\mathrm{A}_{\mathrm{Chla}}^{652} / \mathrm{A}_{\mathrm{Chl} l a}^{675}\right) /\left(\mathrm{A}_{\mathrm{Phs}}^{652} / \mathrm{A}_{\mathrm{Phs}}^{675}\right)\right]$

$\mathrm{d}=\left[\left(\mathrm{A}^{652}{ }_{\mathrm{Chl} a} / \mathrm{A}^{675}{ }_{\mathrm{Chl} a}\right) / \mathrm{c}\right]$

The absorbance ratios $\mathrm{A}^{620} / \mathrm{A}^{675}$ and $\mathrm{A}^{652} / \mathrm{A}^{675}$ for uncontaminated phycobiliprotein buffer solutions were determined disrupting $M$. aeruginosa cells with the freeze-thawing procedure described in section "Phycobiliprotein extraction". Phycobiliprotein solutions with 15 different concentrations (the absorbance at $620 \mathrm{~nm}$ of the solutions varied from about 0.050 to 0.570 ) were prepared by diluting the stock solutions. For each solution, the ab- sorbance spectrum was measured, and the ratios calculated.

The same absorbance ratios for uncontaminated (i.e., phycobiliprotein-free) Chl $a$ were determined applying extraction procedures 1 and deriving these values from the absorbance spectrum of Chla in 90\% acetone (3 differently diluted solutions were used, whit absorbance ranging from 0.090 to 0.312 ), opportunely shifted (11 nm shift) to match the bands position in buffer (Fig. 1).

The absorbance ratios of uncontaminated Chla buffer solutions were determined as well: i) applying extraction procedures 1 and diluting small aliquots of the $90 \%$ acetone Chl $a$ concentrated extract in buffer (the absorbance spectrum was $4 \mathrm{~nm}$ shifted to match the bands position of Chla extracted directly in buffer); ii) preparing Chla buffer solutions following extraction procedures $2 \mathrm{a}$ and $2 b$, avoiding the use of organic solvents.

Six Chla buffer solutions with different concentrations (the absorbance at $675 \mathrm{~nm}$ of the solutions varied from about 0.058 to 0.235 ) were prepared following extraction procedure 1,6 Chla solutions (the absorbance at $675 \mathrm{~nm}$ of the solutions varied from about 0.065 to 0.344 ) were prepared following extraction procedure $2 \mathrm{a}$ and $12 \mathrm{Chl} a$ solutions (the absorbance at $675 \mathrm{~nm}$ of the solutions varied from about 0.096 to 0.622 ) following extraction procedure $2 b$.

For each set of solutions, the absorbance spectrum was measured, and the ratios calculated.

Finally, PC and APC concentration $\left(\mathrm{mg} \mathrm{mL}^{-1}\right)$ was determined introducing $\mathrm{A}^{620}{ }_{\text {Phs }}$ and $\mathrm{A}^{652}{ }_{\text {Phs }}$ in the Bennett and Bogorad equations (Bennett and Bogorad, 1973):

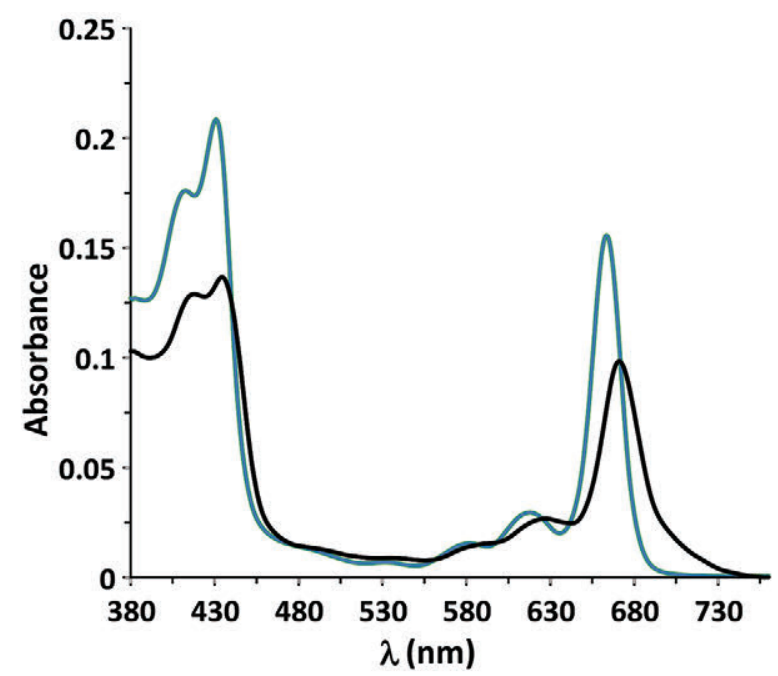

Fig. 1. Absorbance spectra of two Chla solutions of equal concentration (green: 90\% acetone, black: phosphate buffer), prepared from a concentrated Chla solution in $90 \%$ acetone. 
$[\mathrm{PC}]=\left(\mathrm{A}_{\mathrm{Phs}}^{620}-0.474 \mathrm{~A}_{\mathrm{Phs}}^{652}\right) / 5.34$

$[\mathrm{APC}]=\left(\mathrm{A}_{\text {Phs }}^{652}-0.208 \mathrm{~A}_{\text {Phs }}^{620}\right) / 5.09$

\section{Calculation of the error (\%) on phycobiliprotein concentration}

The error (\%) on phycobiliprotein concentration was calculated by applying the following equations:

$$
\begin{aligned}
& E(\%)=\frac{[\mathrm{PC}]_{\mathrm{meas}}^{\text {Chla }}\left(\frac{\mathrm{mg}}{\mathrm{mL}}\right)-[\mathrm{PC}]_{\text {contr }}\left(\frac{\mathrm{mg}}{\mathrm{mL}}\right)}{[\mathrm{PC}]_{\text {contr }}\left(\frac{\mathrm{mg}}{\mathrm{mL}}\right)} \times 100 \\
& \mathrm{E}(\%)=\frac{[\mathrm{PC}]_{\text {corr }}^{\mathrm{Chl} a}\left(\frac{\mathrm{mg}}{\mathrm{mL}}\right)-[\mathrm{PC}]_{\text {contr }}\left(\frac{\mathrm{mg}}{\mathrm{mL}}\right)}{[\mathrm{PC}]_{\text {contr }}\left(\frac{\mathrm{mg}}{\mathrm{mL}}\right)} \times 100 \\
& \mathrm{E}(\%)=\frac{[\mathrm{APC}]_{\text {meas }}^{\text {Chla }}\left(\frac{\mathrm{mg}}{\mathrm{mL}}\right)-[\mathrm{APC}]_{\text {contr }}\left(\frac{\mathrm{mg}}{\mathrm{mL}}\right)}{[\mathrm{APC}]_{\text {contr }}\left(\frac{\mathrm{mg}}{\mathrm{mL}}\right)} \times 100 \text { (eq. 7) } \\
& \mathrm{E}(\%)=\frac{[\mathrm{APC}]_{\text {corr }}^{\mathrm{Chla}}\left(\frac{\mathrm{mg}}{\mathrm{mL}}\right)-[\mathrm{APC}]_{\mathrm{contr}}\left(\frac{\mathrm{mg}}{\mathrm{mL}}\right)}{[\mathrm{APC}]_{\text {contr }}\left(\frac{\mathrm{mg}}{\mathrm{mL}}\right)} \times 100 \text { (eq. 8) }
\end{aligned}
$$

$[\mathrm{PC}]_{\text {meas }}^{\mathrm{Chl} a}$ and $[\mathrm{APC}]_{\text {meas }}^{\mathrm{Chl} a}$ indicate $\mathrm{PC}$ and APC concentration of solutions contaminated by Chla. Phycobiliprotein concentration was determined applying Bennett and Bogorad eq. (3) and (4) without correcting Chla interference.

\section{$[\mathrm{PC}]_{\text {corr }}^{\mathrm{Chl} a}$ and $[\mathrm{APC}]_{\text {corr }}^{\mathrm{Chl} a}$ indicate PC and APC concen-} tration of solutions contaminated by Chla. Phycobiliprotein concentration was determined after correcting the absorbance of PC and APC from Chla contribution (exploiting eq. 1 and 2, or rather 1a and 2a, see below) before applying Bennett and Bogorad eq. (3) and (4).

$[\mathrm{PC}]_{\text {contr }}$ and $[\mathrm{APC}]_{\mathrm{contr}}$ indicate PC and APC concentration of the reference (Chla-free) phycobiliprotein solutions.

Reference solutions and the correspondent Chla contaminated solutions contained the same amount of PC and APC.

\section{RESULTS}

The absorbance ratios $\mathrm{A}^{620} / \mathrm{A}^{675}$ and $\mathrm{A}^{652} / \mathrm{A}^{675}$ for uncontaminated phycobiliprotein buffer solutions were calculate as described in section "Spectrophotometric equations" The mean values obtained: $\mathrm{A}^{620} / \mathrm{A}^{675}=17.505 \pm 2.491( \pm \mathrm{SD})$ and $\mathrm{A}^{652} / \mathrm{A}^{675}=6.67 \pm 0.663( \pm \mathrm{SD})$ were used to develop the eq. (1) and (2).

Absorbance ratios of uncontaminated Chla, calculated using $90 \%$ acetone Chla solutions, were unsuitable to correct Chla interference when introduced in eq. (1) and (2). The equations were tested on 22 phycobiliproteins/Chl $a$ buffer solutions prepared as described in the section "Methods - Chlorophyll $a$ extraction- procedure 2b" (Supplementary Fig. 1). A comparison of the absorbance spectra of Chla in 90\% acetone and in buffer evidenced not only a shift of the bands but also a different shape. In Fig. 1 the absorbance spectra of two Chl $a$ solutions (green: $90 \%$ acetone, black: phosphate buffer) of equal concentration are shown. The peak at $664 \mathrm{~nm}(90 \%$ acetone solution) is not only red-shifted to $671 \mathrm{~nm}$ in buffer, but also broadened; this later change causes hypochromicity of the band.

Also absorbance ratios calculated for Chla buffer solutions prepared diluting in buffer small aliquots of $\mathrm{Chl} a$ organic solutions (Fig. 1, black curve as an example. Acetone content in buffer solution was always $<6 \%$ ) were unsuitable to correct Chla interference when introduced in equations (1) and (2). As before, the equations were tested on 22 phycobiliproteins/Chla buffer solutions prepared as described in the section "Methods - Chlorophyll $a$ extraction- procedure 2b" (Supplementary Fig. 2).

Chla $\mathrm{A}^{620} / \mathrm{A}^{675}$ and $\mathrm{A}^{652} / \mathrm{A}^{675}$ ratios, calculated for uncontaminated Chla buffer solutions, prepared extracting the pigment directly in buffer, from pellets of M. aeruginosa lacking phycobiliproteins (procedure 2a), turned out ineffective as well, when introduced in eq. (1) and (2). Again, the equations were tested on 22 phycobiliproteins/Chla buffer solutions prepared as described in the section "Methods - Chlorophyll $a$ extraction - procedure 2b" (Supplementary Fig. 3).

Keeping in mind the results just described, we calculated the above ratios from the absorbance spectra of buffer solutions of Chl $a$ extracted following procedure $2 \mathrm{~b}$, i.e., in the presence of phycobiliproteins (e.g., Fig. 2, bluegreen curve), after having subtracted, at the appropriate wavelength, the absorbance contribution due to phycobiliproteins. This absorbance contribution was obtained from Chla-free phycobiliproteins buffer solutions of the corresponding concentrations (e.g., Fig. 2, blue curve). We assumed that the effect of the presence of Chla on the absorbance bands of the phycobiliproteins is negligible. This is a reasonable approximation, considering that such an effect, which could result from a (relative) close interaction between Chla and the bilin pigments, is avoided by the phycobiliprotein tertiary and quaternary structure. In fact, bilin pigments are positioned near, but not on the surface of the protein units (Padyana et al., 2001; Adir and Lerner, 2003), so that a bilin/Chla strong interaction is improbable.

On the other hand, the large phycobiliproteins (having a molecular weight of the order of 100,000 - 200,000 Da) present on their surface various relatively hydrophobic sites, potentially able to interact with the hydrophobic Chla macrocycles and affect the spectroscopic feature of this (in comparison) small molecule (having a molecular weight of about $900 \mathrm{Da}$ ), as we indeed observed. 
A comparison of the absorbance spectra of two Chla buffer solutions obtained with extraction procedures $2 \mathrm{a}$ (Fig. 2, green curve) and 2b (Fig. 2, blue curve) revealed that different processes affected Chl $a$ extraction and/or absorption properties following the two protocols.

Procedure $2 \mathrm{~b}$ turned out to be the most effective to get valid absorbance ratios. The mean values obtained $\left[\mathrm{A}^{620} / \mathrm{A}^{675}=0.212 \pm 0.008( \pm \mathrm{SD}), \mathrm{A}^{652} / \mathrm{A}^{675}=0.247 \pm 0.005\right.$ $( \pm \mathrm{SD})]$ were used to develop the equations (1) and (2), obtaining the final form:

$$
\begin{aligned}
& \mathrm{A}_{\text {Phs }}^{620} 1.012 \mathrm{~A}^{620}{ }_{\text {measured }}-0.215 \mathrm{~A}^{675} \text { measured } \\
& \mathrm{A}_{\text {Phs }}^{652} 1.038 \mathrm{~A}_{\text {measured }}^{652}-0.256 \mathrm{~A}^{675} \text { measured }
\end{aligned}
$$

Also these equations were tested on 22 phycobiliproteins/Chla buffer solutions prepared as described in the section "Methods - Chlorophyll $a$ extraction-procedure $2 \mathrm{~b}$ ". This procedure enabled us to prepare work solutions and a reliable control of the phycobiliprotein solutions, containing the same amount of the two blue pigments. As shown in Fig. 3, a remarkable reduction of Chla bias was achieved. The error increases with Chl $a$ content and can be quite large. For the $M$. aeruginosa extracts used in this study (PC concentration: 0.01186, 0.01957, 0.02744, $0.03954,0.04181 \mathrm{mg} / \mathrm{mL}$; and APC concentration: 0.00276, 0.00507, 0.00718, 0.01177, $0.01203 \mathrm{mg} / \mathrm{mL})$, the error in phycobiliprotein quantification using Bennett and Bogorad eq. (3) and (4) that do not consider simultaneous presence of Chla in the extract varied from $4.2 \%$ to $73.8 \%$ for PC (Fig. 3A, green bullets), and from $24.4 \%$ to $616.9 \%$ for APC (Fig. 3B, green bullets). The error in $\mathrm{PC}$ and APC quantification is considerably reduced if absorbance at $620 \mathrm{~nm}$ and $652 \mathrm{~nm}$ are previously corrected applying eq. (1a) and ( $2 a)$. In this case, the error in phycobiliprotein quantification varied from $-2.0 \%$ to $7.4 \%$ for

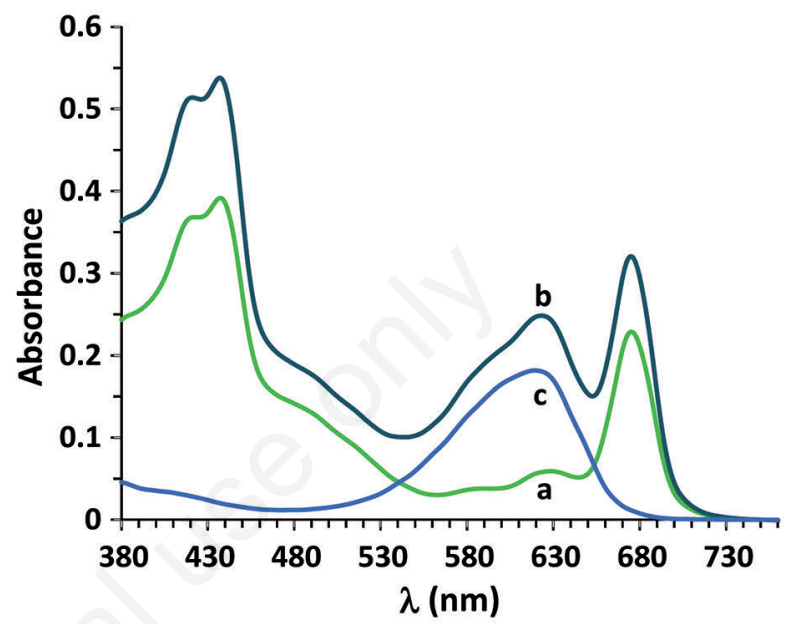

Fig. 2. Absorbance spectra of a) a phosphate buffer extract of "phycobiliprotein-free" pellet suspension of M. aeruginosa (green curve); b) the same amount of pellet suspension extracted diluting it in phycobiliprotein buffer solution (blue-green curve); c) the spectrum of the pure phycobiliproteins is also shown (blue curve). Phycobiliproteins in (b) (blue-green curve) and (c) (blue curve) have the same concentration.
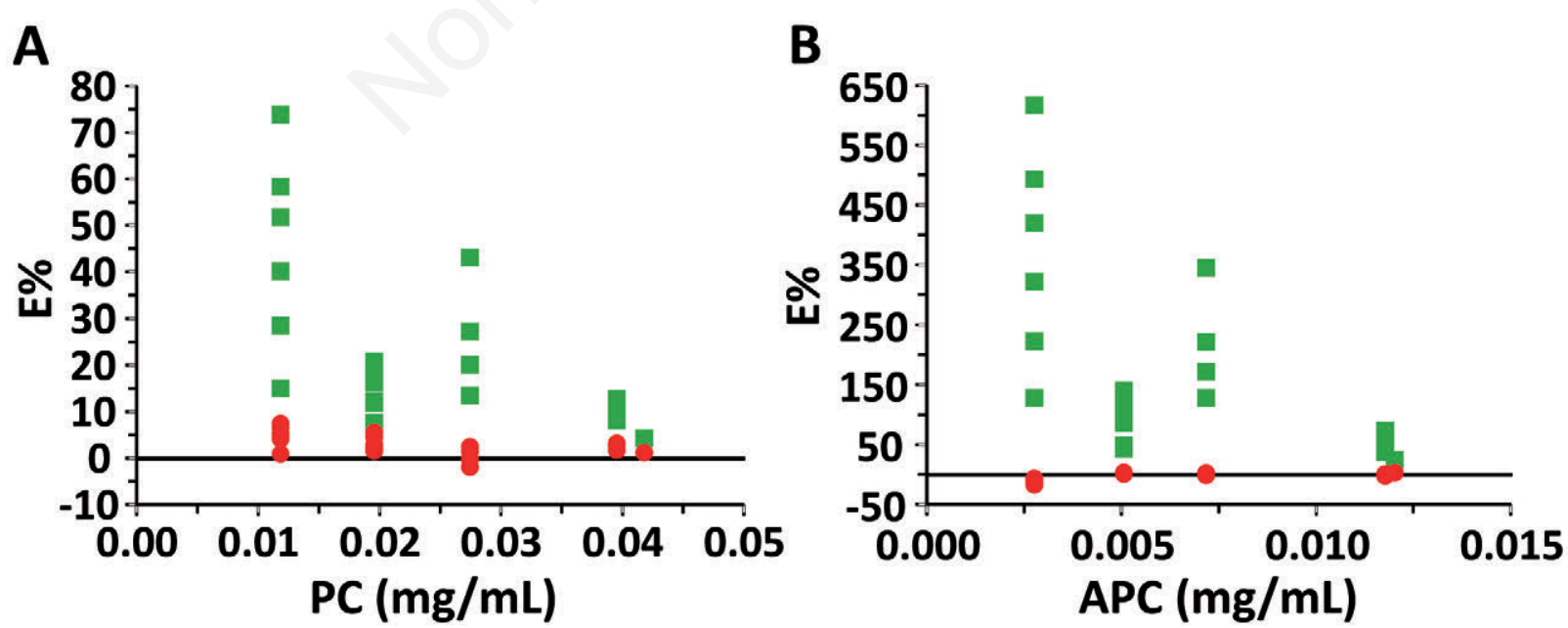

Fig. 3. Errors \% in PC (A) and APC (B) concentration. Green bullets refer to E\% in phycobiliprotein quantification observed when Bennett and Bogorad equations were directly used without correcting Chla interference. Red bullets refer to E\% in phycobiliprotein quantification observed after correcting the absorbance of PC and APC from Chl $a$ contribution [exploiting eq. (1a) and (2a)] before applying Bennett and Bogorad equations. 
PC (Fig. 3A, red bullets), and from $-17.6 \%$ to $3.0 \%$ for APC (Fig. 3B, red bullets).

\section{DISCUSSION}

The development of the corrective equations for phycobiliprotein absorbance required, first, a right evaluation of the absorbance ratios $\mathrm{A}^{620} / \mathrm{A}^{675}$ and $\mathrm{A}^{652} / \mathrm{A}^{675}$ for the phycobiliproteins buffer solutions not contaminated by Chla, and for the Chla buffer solutions not contaminated by phycobiliproteins.

The determination of these ratios for the uncontaminated phycobiliprotein buffer solutions was quite straightforward for PC and APC extracted from M. aeruginosa. In fact, freeze-thawing procedure efficiently disrupted the cells of this cyanobacterium species, and phycobiliproteins were released in buffer, obtaining solutions not contaminated by Chla.

In order to quantify the bias due to chlorophyll $a$ in the extract, we need to measure the absorbance ratios for uncontaminated (i.e., phycobiliprotein-free) Chla in buffer. The usual approach to derive these values from the Chla organic solutions (typically, acetone), opportunely shifted (see, for example, Bidigare et al., 1990; Yacobi et al., 2015) to match the bands position in buffer, was not appropriate here. Introducing these absorbance ratios in eq. (1) and (2), a very poor correction for the Chla bias was obtained. This fact is, very likely, due to the different chemical conditions Chla experiences in buffer solution with respect to acetone or other organic solvents. Chlorophyll $a$ is highly hydrophobic and produces aggregates in buffer solution (Agostiano et al., 2002). The observed broadening and hypochromicity of the Chla absorbance bands in buffer solutions suggests Chl $a$ aggregation. As a consequence, Chl $a$ bands in $90 \%$ acetone respect to those in buffer solution not only are shifted, but exhibit different shapes. Different shapes imply different absorbance ratios, even after having shifted them to match each other.

Further, the absorbance ratios obtained using Chla phosphate buffer solutions, prepared by diluting small aliquots of concentrated Chla in 90\% acetone also produced a poor correction for the Chla bias. An explanation may be attempted by hypothesizing a certain effect of the organic solvent on the aggregation process of Chla in buffer solution, which affects the Chla absorbance features. The bias due to the effect of the organic solvent is evidenced by the position of the absorbance maximum of these Chla solutions, which was found at $671 \mathrm{~nm}$ and not at $675 \mathrm{~nm}$, which is the band maximum position of Chla directly extracted in buffer (procedure $2 \mathrm{a}$ and $2 \mathrm{~b}$ ).

Therefore, Chla phosphate buffer solutions were prepared extracting the pigment directly in buffer from pellets of $M$. aeruginosa lacking phycobiliproteins.

In a first attempt, Chla was extracted in the absence of phycobiliproteins (procedure 2a). Again, when introduced in the eq. (1) and (2), the absorbance ratios $\mathrm{A}^{620} / \mathrm{A}^{675}$ and $\mathrm{A}^{652} / \mathrm{A}^{675}$, obtained following this extraction protocol, did not produce a good correction.

To explain this result, we hypothesized that Chla extraction and aggregation was affected by the presence of the other compounds present in the aqueous solution. Our data supported an enhancement of Chla extraction from the cyanobacterial pellet (following the extraction procedure 2b) and a change of Chl $a$ aggregation pattern in the presence of phycobiliproteins (Fig. 2, blue-green curve versus green curve). The extraction enhancement might be due to interactions between Chla and some less polar portion of the phycobiliproteins (moreover, other proteins and compounds of different nature are present in the solution, and interactions between Chla and these compounds may occur). These interactions may change Chla aggregation pattern and/or modify a little the shapes of the pigment absorbance bands, altering the values of the absorbance ratios we are interested in.

Introducing $\mathrm{A}^{620} / \mathrm{A}^{675}$ and $\mathrm{A}^{652} / \mathrm{A}^{675}$ ratios for uncontaminated phycobiliproteins solutions and uncontaminated Chla solutions, obtained following extraction procedure $2 b$, in eq. (1) and (2), their final form, (1a) and (2a), was developed.

When the apparent PC and APC absorbance values were corrected applying equations (1a) and (2a), before quantifying phycobiliproteins according to Bennett and Bogorad (1973), the error in phycobiliprotein quantification due to Chl $a$ was greatly reduced. In fact, whenever Chla is present in solution, PC and APC contents are overestimated, if they are determined using Bennett and Bogorad eq. (3) and (4) without taking in account Chla presence.

\section{CONCLUSIONS}

We have shown that Chla contamination of phycobiliprotein aqueous extracts can cause large errors in PC and, especially, in APC spectrophotometric quantification.

We elaborated a strategy to minimize such errors, and developed eq. (1a) and (2a) to correct the apparent PC and APC absorbance values, before quantify phycobiliproteins as in Bennett and Bogorad (1973). Indeed, this approach allowed to minimize the error in PC and APC quantification in the cases studied.

The authors of the present paper chose to use as source of PC, APC and Chla the freshwater cyanobacterium $M$. aeruginosa, because it is a potentially toxic species, often developing blooms in eutrophic inland waters. They are however aware that the use of one species only is reductive and additional tests with different cyanobacteria species are needed, as well as investigations on the possible additional bias due to presence of other Chls, e.g., 
$\mathrm{Chl} b$, these chlorophylls are usually found in mixed phytoplankton assemblages. Nevertheless, the author not only believe that this approach is already an important step forward for a more precise quantification of cyanobacteria using PC and APC quantification, but also they believe that the results obtained are important to draw attention on a phenomenon that is often neglected or considered with an oversimplified approach. These results show that certain assumptions commonly used for the spectrophotometric quantification of phycobiliproteins are too simplistic and a deep knowledge of the chemical-physical characteristics of the system is necessary to have a reliable quantification.

\section{ACKNOWLEDGMENTS}

This study was carried out with the financial support of Fondazione CARIPLO (BLASCO Project, Rif. 20141249, 2015-2017). We are indebted to Dr. Emanuela VIAGGIU and Prof. Dr. Roberta CONGESTRI (Laboratory of Biology of Algae, Department of Biology, University of Rome Tor Vergata) for kindly providing the cyanobacterial strain. We are grateful to the anonymous reviewers for their comments and for their help in improving our manuscript.

We are deeply grateful to Dr. Giuseppe Morabito for his support and contribution to this work despite his precarious health conditions. His death is a major loss for the scientific community. We'll miss him as a friend and colleague.

\section{REFERENCES}

Adir N, Lerner N, 2003. The crystal structure of a novel unmethylated form of C-phycocyanin, a possible connector between cores and rods in phycobilisomes. J. Biol. Chem. 278:25926-25932.

Agostiano A, Cosma P, Trotta M, Monsù-Scolaro L, Micali N, 2002. Chlorophyll a behavior in aqueous solvents: formation of nanoscale self-assembled complexes. J. Phys. Chem. B 106:12820-12829.

Bennett A, Bogorad L, 1973. Complementary chromatic adaptation in a filamentous blue-green alga. J. Cell Biol. 58: 419-435.

Berns DS, MacColl R, 1989. Phycocyanin in physical chemical studies. Chem. Rev. 89:807-825.

Bidigare RR, Ondrusek ME, Morrow JH, Kiefer DA, 1990. Invivo absorption properties of algal pigments. Proc. SPIE 1302, Ocean Optics X, doi: 10.1117/12.21451.

Bresciani M, Giardino C, Bartoli M, Tavernini S, Bolpagni R, Nizzoli D, 2011. Recognizing harmful algal bloom based on remote sensing reflectance band ratio. J. Appl. Remote Sens. 5:053556.

Bruno M, Melchiorre M, Messineo V, 2005. [Caratteristiche e diffusione delle fioriture tossiche nelle acque dolci Italiane]. In:
D. Mattei, S. Melchiorre, V. Messineo and M. Bruno (eds.), [Diffusione delle fioriture algali tossiche nelle acque italiane: gestione del rischio ed evidenze epidemiologiche].[Report in Italian]. Rapporti ISTISAN 05/29, pp. 1-10.

Cohen-Bazire G, Bryant DA, 1982. Phycobilisomes: composition and structure, 143-190. In: N.G. Carr, B.A. Whitton (eds.), The biology of cyanobacteria. University of California Press, Berkeley.

Chorus I, Bartram J, 1999. Toxic cyanobacteria in water: a guide to public health consequences, monitoring and management. E and FN Spon, on behalf of WHO, London and New York

De Marsac NT, Houmard J, 1988. Complementary chromatic adaptation: Physiological conditions and action spectra. Method. Enzymol. 167:318-328.

Escoffier N, Bernard C, Hamlaoui S, Groleau A, Catherine A, 2015. Quantifying phytoplankton communities using spectral fluorescence: the effects of species composition and physiological state. J. Plankton Res. 37:233-247.

Gantt E, 1975. Phycobilisomes: Light-harvesting pigment complexes. Bioscience 25:781-788.

Glazer AN, 1988. Phycobiliproteins, p. 291-303. In: L. Packer and A.N. Glazer (eds.), Methods in enzymology. Academic Press, San Diego.

Glazer AN, Hixson CS, 1977. Subunit structure and chromophore composition of rhodophytan phycoerythrins. Porphyridium cruentum B-phycoerythrin and b-phycoerythrin. J. Biol. Chem. 252:32-42.

Horváth H, Kovács AW, Riddick C, Présing M, 2013. Extraction methods for phycocyanin determination in freshwater filamentous cyanobacteria and their application in a shallow lake. Eur. J. Phycol. 48:278-286.

Kasinak JME, Holt BM, Chislock MF, Wilson AE, 2015. Benchtop fluorometry of phycocyanin as a rapid approach for estimating cyanobacterial biovolume. J. Plankton Res. 37: 248-257.

Lawrenz E, Fedewa EJ, Richardson TL, 2011. Extraction protocols for the quantification of phycobilins in aqueous phytoplankton extracts. J. Appl. Phycol. 23:865-871.

Li Y, Lin Y, Garvey CJ, Birch D, Corkery RW, Loughlin PC, Scheer H, Willows RD, Chen M, 2016. Characterization of red-shifted phycobilisomes isolated from the chlorophyll fcontaining cyanobacterium Halomicronema hongdechloris. Biochim. Biophys. Acta 1857:107-114.

Macário IP, Castro BB, Nunes MI, Antunes SC, Pizarro C, Coelho C, Goncalves F, de Figueiredo DR, 2015. New insights towards the establishment of phycocyanin concentration thresholds considering species-specific variability of bloom-forming cyanobacteria. Hydrobiologia 757:155-165.

MacColl R, 1983. Stability of allophycocyanin's quaternary structure. Arch. Biochem. Biophys. 223:24-32.

MacColl R, 1998. Cyanobacterial phycobilisomes. J. Struct. Biol. 124:311-334.

MacIntyre HL, Lawrenz E, Richardson TL, 2011. Taxonomic discrimination of phytoplankton by spectral fluorescence, (chap 7) p. 129-169. In: D.J. Suggett, O. Prášil and M.A. Borowitzka (eds.) Chlorophyll fluorescence techniques in aquatic sciences: methods and applications. Springer.

Mishra S, Mishra DR, 2014. A novel remote sensing algorithm to quantify phycocyanin in cyanobacterial algal blooms. Environ. Res. Lett. 9:114003. 
Myers J, Kratz WA, 1955. Relations between pigment content and photosynthetic characteristics in a blue-green alga. J. Gen. Physiol. 39:11-22.

Ogashawara I, Mishra DR, Mishra S, Curtarelli MP, Stech JL, 2013. A performance review of reflectance based algorithms for predicting phycocyanin concentrations in inland waters. Remote Sens. 5:4774-4798.

Padyana AK, Bhat VB, Madyastha KM, Rajashankar KR, Ramakumar S, 2001. Crystal structure of a light-harvesting protein C-phycocyanin from Spirulina platensis. Biochem. Biophys. Res. Commun. 282:893-898.

Quesada A, Vincent WF, 1993. Adaptation to the light regime within Antarctic cyanobacterial mats. [Article in German]. Verh. int. Ver. Limnol. 25:960-965.

Richardson TL, Lawrenz E, Pinckney JL, Guajardo RC, Walker EA, Paerl HW, MacIntyre HL, 2010. Spectral fluorometric characterization of phytoplankton community composition using the Algae Online Analyser. Water Res. 44:2461-2472.

Rippka RM, Deruelles J, Waterbury JB, Herdman M, Stanier RY, 1979. Generic assignments, strain histories and properties of pure cultures of cyanobacteria. J. Gen. Microbiol. 111:1-61.

Ritchie RJ, 2006. Consistent sets of spectrophotometric chlorophyll equations for acetone, methanol and ethanol solvents. Photosynth. Res. 89:27-41.

Sarada RMGP, Pillai MG, Ravishankar GA, 1999. Phycocyanin from Spirulina sp: influence of processing of biomass on phycocyanin yield, analysis of efficacy of extraction meth- ods and stability studies on phycocyanin. Process Biochem. 34:795-801.

Schalles JF, Yacobi YZ, 2000. Remote detection and seasonal patterns of phycocyanin, carotenoid and chlorophyll pigments in eutrophic waters. Ergeb. Limnol. 55:153-168.

Seppälä J, Ylöstalo P, Kaitala S, Hällfors SS, Raateoja M, Maunula P, 2007. Ship-of-opportunity based phycocyanin fluorescence monitoring of the filamentous cyanobacteria bloom dynamics in the Baltic Sea. Estuar. Coast. Shelf S. 73:489-500.

Simis SGH, Ruiz-Verdu A, Dominguez-Gomez JA, PenaMartinez R, Peters SWM, Gons HJ, 2007. Influence of phytoplankton pigment composition on remote sensing of cyanobacterial biomass. Remote Sens. Environ. 106:414-427.

Yacobi YZ, Koehler J, Leunert F, Gitelson A, 2015. Phycocyanin-specific absorption coefficient: Eliminating the effect of chlorophylls absorption. Limnol. Oceanogr.-Meth. 13: 157-168.

Zhao W, Xie J, Xu X, Zhao J, 2015. State transitions and fluorescence quenching in the cyanobacterium Synechocystis PCC 6803 in response to changes in light quality and intensity. J. Photochem. Photobiol. B 142:169-177.

Zhu Y, Chen XB, Wang KB, Li YX, Bai KZ, Kuang TY, Ji HB, 2007. A simple method for extracting C-phycocyanin from Spirulina platensis using Klebsiella pneumoniae. Appl. Microbiol. Biot. 74:244-248.

Zimba PV, 2012. An improved phycobilin extraction method. Harmful Algae 17:35-39. 